\title{
The Impact of Emotional Intelligence on Job Performance During COVID-19 Crisis: A Cross-Sectional Analysis
}

This article was published in the following Dove Press journal: Psychology Research and Behavior Management

\section{Wadi B Alonazi (D)}

Health and Hospital Administration College of Business Administration, King Saud University, Riyadh I I587, Saudi Arabia
Correspondence: Wadi B Alonazi Health and Hospital Administration, College of Business Administration, King Saud University, PO Box 7III5, Riyadh

I I587, Saudi Arabia

Email waalonazi@ksu.edu.sa
Background: During a pandemic, healthcare professionals encounter various health hazards that affect their personal life and workplace. Emotional intelligence (EI) has a substantial impact on nurses' success and performance in the healthcare industry. However, previous research studies report inconsistent findings regarding how different levels of EI affect job performance (JP), particularly during pandemics. The present study contributes to the literature on this contemporary topic by investigating the impact of EI on JP among nurses during COVID-19 crisis management in Saudi Arabia (SA).

Methods: In a convenience sampling, 340 nurses from three tertiary hospitals completed an online survey assessing EI and JP during COVID-19 climax levels in March and April, 2020. Only nurses who had direct contact with patients diagnosed with COVID-19 were eligible. The Wong \& Law EI scale (WLEIS) was used in a cross-sectional design to determine participants' EI. Empirically, JP was measured by the Individual Work Performance Questionnaire (IWPQ). Data analysis was performed using SPSS statistical software version 20.0 (IBM Corp).

Results: Generally, nurses reported, out of a 5-point Likert scale, moderate to high levels of $\mathrm{EI}(\mathrm{M}=3.99, \mathrm{SD}=0.434)$. Nurses in critical care units demonstrated the highest levels of EI, followed by nurses in intensive care, neonatal intensive care, then general nurses. Nurses working in respiratory therapy demonstrated the lowest levels. Across all groups during crisis, nurses reported a significant impact of EI on JP $(\beta=0.389, \mathrm{p}<0.01)$.

Conclusion: Nurses reported satisfactory levels of EI, and most of their practices were aligned with national standards during COVID-19, but slightly in inverse to EI. However, more research is necessary to understand the greater impact of stressors influencing JP to the extent that levels of EI are no longer satisfactory.

Keywords: emotional intelligence, nurses, job performance, COVID-19

\section{Background}

During crisis, practices are turbulent, and an individual's interest is often at odds with collective interests. ${ }^{1}$ The concept of emotional intelligence (EI) is normally associated with practice, and particularly within the scope of nursing, reflective of traumatic impact on various job experiences. ${ }^{2}$ Currently, EI is widely regarded as a central measurement affecting job performance (JP). ${ }^{3,4}$ This could be demonstrated as EI describes an individual's ability to manage emotions alongside cognitive processes as a means of motivating themselves with respect to both distal and proximal goals. ${ }^{5,6}$ To manage and work with one's emotions, the effective practice 
of EI is something that can be taught, and Goleman argues that it ought to be a dominant component of professional development initiatives. He is convinced that job-specific expertise alone cannot improve performance. Rather, increased levels of EI are necessary to allow individuals to use novel skills successfully. Improving EI can thus drive balanced increases in both professional success and social performance. ${ }^{6,7}$

Goleman's effort has been the subject of significant research over the last two decades. A review of the current literature indicates that fundamental levels of EI may vary among practitioners of different professions, especially among healthcare professionals. ${ }^{8}$ In addition, some components of EI are individual-centered; everyone is intrinsically motived by certain psychological stages like confidence, confrontation, and the nature of stressors such as absenteeism and traumas. ${ }^{9,10}$

The same is true for healthcare providers, who rely on EI to a high degree. This is absolute for those especially in positions requiring direct contact with patients, like physicians and nurses. Each healthcare position requires a specific set of competencies, and particularly human resources for employees to function adequately, and EI plays a substantial role among these. ${ }^{11}$

In the healthcare context, in order to understand the factors driving institutional success, it is also imperative to accurately assess levels of JP. This can be understood as an attitude reflecting how an employee feels about their current job, and normally summarizes how the individual relates to the various aspects of their position. ${ }^{12}$ Additionally, JP is a reflection of how healthcare providers contribute effectively to their teams and is regarded as contingent on both internal satisfaction and EI. ${ }^{13}$

In social and professional psychology, EI is regarded as a fundamental predictor of organizational outcomes, especially JP. For instance, emotions play a vital role in the practice of nursing, which demands both technical and psychological forms of expertise in patient care. ${ }^{14}$ Therefore, an individual who can thrive in a nursing role, and coordinate closely with doctors and other healthcare providers, is necessarily someone with sufficient EI to recognize and take advantage of his/her sentiments and thoughts. ${ }^{15}$ In addition, the nursing profession is predominantly female, and previous studies indicate that women have higher average EI than men. ${ }^{14,15}$

The relationship between EI and JP is not a novel topic of study, as several previous investigations have attempted to better understand EI's involvement in moderating performance in the workplace. Several studies have explored quantifiable links between the indices and other characteristics that collectively lead to productive, professional, and economic activity. ${ }^{16,17}$ Also, previous studies have dealt primarily with management in general, but some have addressed healthcare services, including the field of nursing. In both contexts, EI is considered to be one of the main elements responsible for shaping performance. ${ }^{18}$ However, agreement is less widespread beyond this basic point. Since the emergence of EI as a concept, some health organizational behavioral researchers have reported varying results with respect to its effects on organizational culture. ${ }^{19,20}$ Some studies have argued that EI is more valuable than technical skills or cognitive abilities. ${ }^{21-23}$ For instance, social consciousness and relationship management are indispensable skills for successful leadership in any domain. ${ }^{24,25}$ These skills include elements of cooperation, team awareness, conflict management, and sympathy. ${ }^{26}$ According to EI theory, leaders evincing these abilities have far-reaching effects on their organizations. Senior healthcare executives with high EI influence intermediate managers, who in turn influence onthe-ground staff members; in hospitals, these are the frontline caregivers. Trivellas et al investigated the impact of EI on organizational performance among nursing staff working in the healthcare sector and found a strong impact of EI on organizational performance linked directly to retention and job commitment. ${ }^{27}$ However, more exposure to crisis may lead to less EI among nurses, and in particular those in medical sections. ${ }^{28,29}$

The Saudi healthcare system confronted a pandemic in early 2020; the government has taken serious measures to minimize risks including partial, then full, curfew, and encouraging social distancing policy. ${ }^{30,31}$ This has led to pressure on healthcare professionals, particularly nurses, as they represent the first line against such risk. ${ }^{32}$ Their personal and social needs were drastically affected by many patients admitted to the hospitals. The below figure is a summary of reported cases during the novel COVID19 in Saudi Arabia, Figure 1.

Generally, Saudi nurses are reticent in explicitly expressing how they feel; this is particularly the case in medical settings where behavior is often more formal. ${ }^{33,34}$ Emotional skills, and their effects on JP, are seldom addressed in Saudi health organizations. Thus, within Saudi hospitals, EI is not a widely understood element of job performance among nurses working in various departments. 


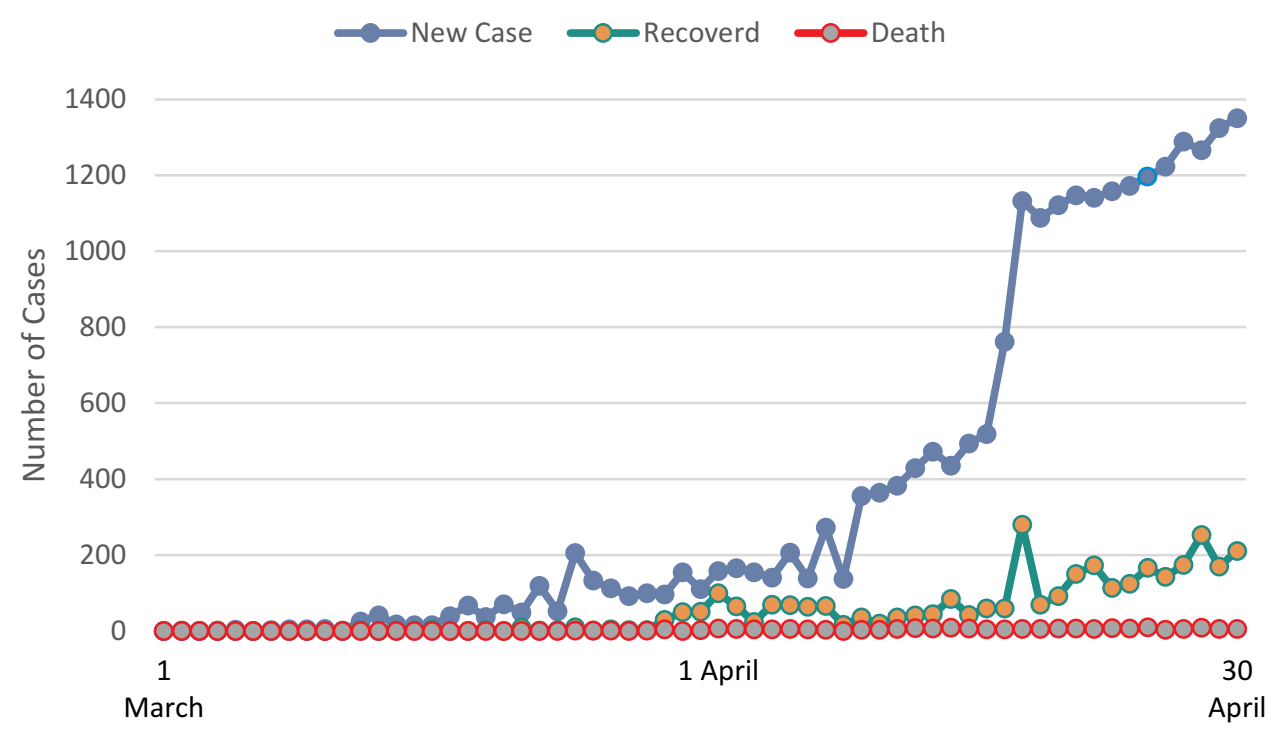

Figure I Novel COVID-19 cases in Saudi Arabia during March and April 2020.

Simply, previous research has demonstrated that nurses' intrapersonal and interpersonal motives affect their job preferences. The present work is designed to be the first to consider such influence during pandemics. Additionally, this research introduces the impact of different constructs on different nurses' professions. The primary objective of this study was to explore the impact of EI on JP among nurses directly treating patients diagnosed with confirmed cases of COVID-19.

\section{Methods}

In a quantitative study, data were collected from three large tertiary hospitals in Saudi Arabia. The study's participants were hospital nurses involved directly with medical and non-medical services for patients diagnosed with COVID-19 during March and April, 2020.

\section{Participants}

Each one of the three settings has employed an average of 800 skillful nurses. The hospitals attract highly qualified professionals, especially those with medical certification from North America and Europe. After obtaining approval from the Institute Review Board (IRB-20-04E), eligible participants were identified based on the central data from each nursing department. Other eligibility criteria included employment at the hospital for at least 24 months prior to the beginning of the study, and regular provision of medical or non-medical services in tertiary care capacities to COVID-19 patients.

The study used convenient sampling to select the eligible respondents. The minimum sample size was determined to be 341 , based on the total available population of 3.000, using a Krejcie and Morgan table. ${ }^{35}$ An online survey was made available to the selected respondents through email message, accompanied by a confidentiality statement and a description of privacy measures taken, which included the complete anonymity of all responses. Written consent was not obtained using a purpose-specific document. Replying to the email indicating interest was understood to constitute consent to participate. The survey was emailed to a total of 400 hospital employees, of which 340 completed valid responses that were included in the current analysis.

To ensure that the survey was free from common method bias, Harman's single factor test was applied to the responses. The first factor accounted for $28.77 \%$ of the variance, which was less than the threshold level of $50 \%$ of total variance explained above, of which the data could reasonably have been treated as subject to bias. ${ }^{36}$

\section{Measure}

The online survey itself was designed with the goal of investigating whether any relationships existed between EI levels (independent variable) and levels of JP (dependent variables). The survey had three major parts. The first part consisted of socio-demographic information and the second consisted of the Wong \& Law EI scale (WLEIS), which is a widely used measure with high validity and reliability. ${ }^{21}$ Part three contained items intended to assess JP adapted from Koopmans and others. ${ }^{37}$ Generally, a psychometric response scale was 
used in which responders specified their level of agreement to a statement, typically in five points: (1) Strongly disagree; (2) Disagree; (3) Neither agree nor disagree; (4) Agree; (5) Strongly agree.

EI was evaluated using a composite measure consisting of four indices: self-emotion appraisal (SEA), others' emotion appraisal (OEA), use of emotion (UOE), and regulation of emotion (ROE). JP was measured on a one-dimensional scale.

Prior to the analysis, the instrument itself was assessed by three researchers in the field and a survey expert, and its applicability was examined in a pilot study. The pilot was conducted using the debriefing method based on personal interviews suggested by Hunt and others, and respondents who participated in it were excluded from the final data analysis. ${ }^{38}$ The objectives of the pre-testing were explained to the respondents, who were then asked to evaluate the items used on several criteria, including the clarity of syntax, sequencing and layout of the questionnaire, appropriateness of the items used to measure the variables they were intended to measure, and appropriateness of the items used contextually.

\section{Procedure}

Within 2 months, 400 emails with a link to the online survey were sent over the hospitals' local intranet to selected nurses based on the eligibility criteria. Participants completed the survey during March and April, 2020. No reminder email was sent out during this time; the survey was entirely self-administered. Data were analyzed using SPSS, version 20.

\section{Results}

Out of 400 health providers who received the survey by email, only 340 provided valid responses that were used in the present study, yielding an $85.5 \%$ response rate. The majority of the respondents were female $(76 \%)$, and the largest professional group consisted of members of the $\mathrm{CC}$ 120 ; the lowest was from RT $33(35.2 \%, 9.7 \%$, respectively), as shown in Table 1.

To assess the average levels of EI and JP within each professional group, descriptive statistics were calculated in SPSS, including the mean and standard deviation of scores in each domain. The results of this analysis are presented in Table 2 .
Table I The Socio-Demographic Characteristics of the Participants

\begin{tabular}{|c|c|c|c|c|c|c|}
\hline \multirow{3}{*}{$\begin{array}{l}\text { Profession } \\
\text { Field }\end{array}$} & \multicolumn{4}{|c|}{ Gender } & \multirow{2}{*}{\multicolumn{2}{|c|}{ Overall }} \\
\hline & \multicolumn{2}{|l|}{$\begin{array}{l}\text { Male } \\
(n=82)\end{array}$} & \multicolumn{2}{|c|}{$\begin{array}{l}\text { Female } \\
(n=258)\end{array}$} & & \\
\hline & Count & $\%$ & Count & $\%$ & Count & $\%$ \\
\hline ICU & 21 & 26 & 24 & 9.3 & 45 & 13.2 \\
\hline RT & 8 & 9 & 25 & 9.7 & 33 & 9.7 \\
\hline $\mathrm{NICU}$ & 20 & 24 & 30 & 11.6 & 50 & 14.7 \\
\hline $\mathrm{CC}$ & 12 & 15 & 108 & 41.9 & 120 & 35.3 \\
\hline General & 21 & 26 & 71 & 27.5 & 92 & 27.1 \\
\hline
\end{tabular}

Abbreviations: ICU, intensive care unit; RT, respiratory therapy; NICU, neonatal intensive care unit; $\mathrm{CC}$, critical care unit.

Table 2 The Mean and Standards Deviation of the Subjects' Response Towards El and JP

\begin{tabular}{|l|l|l|l|l|}
\hline \multirow{2}{*}{ Profession Field } & \multicolumn{2}{l|}{ EI } & \multicolumn{2}{l|}{ JP } \\
\cline { 2 - 5 } & M & SD & M & SD \\
\hline ICU $(n=45)$ & 3.99 & 0.44 & 3.89 & 0.49 \\
RT $(n=33)$ & 3.82 & 0.27 & 3.71 & 0.56 \\
NICU $(n=50)$ & 3.98 & 0.46 & 3.90 & 0.59 \\
CC $(n=120)$ & 4.08 & 0.43 & 3.91 & 0.45 \\
General $(n=92)$ & 3.93 & 0.45 & 3.92 & 0.55 \\
Overall & 3.99 & 0.41 & 3.89 & 0.53 \\
\hline
\end{tabular}

Abbreviations: El, emotional intelligence; JP, job performance; M, mean; SD, standard deviation.

\section{Instrument Adaptation}

Factor analysis is a data reduction technique used to determine whether multiple items are measuring the same underlying cause. During factor analysis, candidate factors with eigenvalues of less than one are normally rejected, while those with eigenvalues greater than one are retained for further analysis. Factor analysis was conducted on the survey results, followed by reliability testing to determine the degree to which the measures employed were free from random errors. Cronbach's alpha was applied to determine whether the items in each group were positively related to one another. A Cronbach's alpha value of above or equal to $70 \%$ is considered to indicate a high reliability. ${ }^{39}$ The results of the factor and reliability analyses are presented in Table 3.

The factor analysis was conducted on items from the EI and JP sections of the survey. It applies a percentage of variance criterion approach based on accounting for a specified cumulative percentage of total variance in test results by extracting successive factors. Using this method, within the EI section, the four items related to SEA were 
Table 3 Factor and Reliability Analysis of El and JP

\begin{tabular}{|c|c|c|c|}
\hline Items & Loading & Communality & $\alpha$ \\
\hline \multicolumn{4}{|l|}{ Emotional Intelligence (EI) } \\
\hline \multicolumn{4}{|l|}{ Self-Emotional Appraisal } \\
\hline Have a good sense of why I have certain feelings most of the time & 0.644 & 0.486 & \\
\hline Have good understanding of my own emotions towards my colleagues & 0.769 & 0.665 & \\
\hline Really understand what I feel towards my colleagues & 0.857 & 0.769 & \\
\hline Always know whether or not I am happy in the hospital & 0.732 & 0.620 & \\
\hline$($ Eigenvalue $=5.227 ;$ Variance $=32.66 \%)$ & & & 0.801 \\
\hline \multicolumn{4}{|l|}{ Other's Emotional Appraisal } \\
\hline Always know my colleague's emotions from their behaviour & 0.616 & 0.460 & \\
\hline Good observer of my colleague's emotions & 0.718 & 0.586 & \\
\hline Sensitive to the feelings and emotions of my colleagues & 0.665 & 0.474 & \\
\hline Good understanding of the emotions of my colleagues & 0.786 & 0.685 & \\
\hline$($ Eigenvalue $=1.3 \mathrm{II} ;$ Variance $=8.193 \%)$ & & & 0.724 \\
\hline \multicolumn{4}{|l|}{ Use of Emotions } \\
\hline Always set goals for myself and then try my best to achieve them & 0.687 & 0.540 & \\
\hline My work, I always tell myself I am a competent person & 0.389 & 0.343 & \\
\hline My daily work, I am a self-motivated person & 0.790 & 0.659 & \\
\hline I would always encourage myself to try my best & 0.702 & 0.591 & \\
\hline$($ Eigenvalue= $1.795 ;$ Variance $=11.219 \%)$ & & & 0.711 \\
\hline \multicolumn{4}{|l|}{ Regulations of Emotions } \\
\hline I am able to control my temper and handle difficulties rationally. & 0.835 & 0.729 & \\
\hline I am quite capable of controlling my own emotions & 0.814 & 0.737 & \\
\hline I can always calm down quickly when I am very angry & 0.492 & 0.554 & \\
\hline I have good control of my own emotions & 0.523 & 0.630 & \\
\hline$($ Eigenvalue $=1.195 ;$ Variance $=7.468 \%)$ & & & 0.778 \\
\hline \multicolumn{4}{|l|}{$(\mathrm{KMO}=0.820 ;$ Total Variance $=59.548 \%)$} \\
\hline \multicolumn{4}{|l|}{ Job Performance (JP) } \\
\hline Quality of my work is very good & $0.64 I$ & 0.461 & \\
\hline Always fulfill my responsibilities & 0.801 & 0.657 & \\
\hline Cope well with difficult situations and setbacks at work & 0.782 & 0.617 & \\
\hline Complained about unimportant matters at work & 0.660 & 0.437 & \\
\hline Eigenvalue= $1.81 \mathrm{I} ;$ Variance $=18.114 \%)$ & & & 0.717 \\
\hline
\end{tabular}

Notes: $r, 0.529 ; p<0.01$.

loaded onto factor number one. The four items related to OEA were loaded onto factor number three; the four items related to UOE were loaded onto factor number two, and the remaining four items, which were related to ROE, were loaded onto factor number four. Together, these items accounted for $59.548 \%$ of the total variance.

The four items assessing JP were distributed over factor number two, accounting for $18.1 \%$ of total variance. The Cronbach's alpha values for all items were above $70 \%$. The Varimax rotation simply approved the loadings of specific variables and specifically identified the factor upon which data were loaded, aiming at an assortment of shared variance among EI components.
A simple regression matrix was constructed to examine the strength of relations among the indices, as shown in Table 4.

Table 4 displays the prediction of EI and JP. Both were statistically significant and moderately positive (EI and JP:

Table 4 Nurses' El and JP During COVID-I9 at a Tertiary Hospital

\begin{tabular}{|l|l|l|l|l|l|}
\hline Variables & $\mathbf{B}$ & $\mathbf{9 5 \%} \mathbf{C l}$ & $\boldsymbol{\beta}$ & $\mathbf{t}$ & $\mathbf{P}$ \\
\hline Constant & 1.402 & $-4.06-13.8 \mathrm{I}$ & & 6.397 & 0.000 \\
El & 0.623 & $0.26-1.49$ & 0.526 & $\mathrm{II} .4 \mathrm{I3}$ & 0.000 \\
\hline
\end{tabular}

Note: $R^{2}, 0.277$.

Abbreviation: $\mathrm{Cl}$, confidence interval for $\mathrm{B}$. 
$\mathrm{p}<0.05, \mathrm{r}=526$ ). In addition, the change in EI has been reported to make a difference in the change of JP by slightly more than one-fourth (the regression model: $\mathrm{JP}=1.402+0.623(\mathrm{EI})$ and about $28 \%$ of the variation in $\mathrm{JP}$ is explained by variation in EI).

\section{Discussion}

The primary objective of this study was to explore the EI among nurses who had direct contact with inpatients diagnosed with novel COVID-19. The secondary objective was to explore the effects of EI on JP when dealing with such a crisis. The results of this study suggest that a high level of EI was typical among critical care unit nurses, nurses in intensive care units, neonatal intensive care units, then general nurses, and finally, nurses working in respiratory therapy with the lowest levels. The study showed moderate relations between EI and JP, and the latter could be affected by how some nurses perceive their emotions.

This study's findings differ from other recent reports in the literature on this topic, strongly indicating an immediate need for further research to explain these contradictions and better model the phenomena in question, for instance. While Birks et al found similar results concerning levels of EI among various healthcare providers, the present study reported the highest average level of EI among critical care unit nurses. This suggests that high EI may be a prerequisite for finding work in nursing, and that it may exist in many candidates prior to recruitment. In previous major studies, this impression was reinforced during interviews with participants. ${ }^{9,40,41}$ The nature of the nursing profession is that it requires practitioners to be both curing and caring, especially during vulnerable periods or end-of-life care. This aspect of the work very likely amplifies the effects of EI on nurses' performance. Gradually, this reliance on EI may increase their awareness of their own EI-related behaviors, allowing them to actively take part in ensuring the delivery of high-quality interdisciplinary care. ${ }^{10,42}$ More specifically, nurses' effective interactions with patients during end-of-life care could consistently maintain a healing environment in the hospital. Medical staff can pursue their own needs, desires, and aspirations in conjunction with their patients' health improvement and success. Hospital staff, particularly nurses, reflect innately skilled communication of empathy.

But if the importance of EI to the practice of nursing is obvious, other aspects of the situation are still likely to be daunting. The present results attempt to induce basic conclusions regarding the sources and attainment of empathy or other components of EI, or at least how EI is affected by intrinsic and extrinsic factors. The current results are, however, consistent with those of Nightingale et al, who reported that high EI in nurses was associated with both corporeal and emotional caring; administrators and doctors may share such essence of EI, even if they have lower levels of EI. ${ }^{2}$ Strangely, the lowest average level of EI was found among professionals in the allied medical sciences and who support ventilation services, where there is limited opportunity for direct communication with patients. ${ }^{43,44}$

The interpretation of a minor decrease in performance while having a slightly high EI is attributed to the nature of the catastrophe of COVID-19, where many patients are almost at the edge of death. Indeed, exhibiting the skills required to cope with change and respond accordingly to patients' needs is the ultimate goal of the nursing profession. Perhaps coping with clinical situations and enforcing tasks in helpful manners may increase EI, but still, there is a point where nurses can no longer adhere to their emotions. ${ }^{45}$ The evidence-based studies about this pandemic are still in early stages, so we may confront more interpretations regarding the constructs that may emotionally play a vital role in JP.

Again, it is well documented that EI is a predictor of $\mathrm{JP}$, as cited in many research studies, but with some variations. ${ }^{46-48}$ Thus, of all groups of nurses, the assumption has indicated that some healthcare providers' emotions were effective in self-regulation regardless of their assigned roles. The present results are consistent with those reported by Trivellas et al and Mo et al, who found a strong prediction of JP during crisis. ${ }^{27,28}$ The present study is unique, since the duration of data collection was the most devastating period in 2020 where COVID-19 broke through in pandemic form.

However, in some fields, EI scores were linked negatively with measures such as stress despite their positive link to JP. Nonetheless, variation in EI does seem to result in variation in JP (a higher level of EI is associated with a higher level of JP). For instance, Akhtar et al found that EI displayed a strong positive relationship with JP, which was amplified when organizational support for EI training increased considerably. ${ }^{49,50}$ Similar results have been reported in this investigation, as the sample demonstrated positive results of EI and JS among the participants. The significance of this is that the present results are consistent with other investigations, many of which employed large sample sizes and demonstrated positive relations between 
EI and JP among their participants. This finding is congruent with psychological and vocational theories suggesting that full engagement in one's occupation may create strong feelings of happiness, adequacy, and overall satisfaction. $^{51}$

\section{Limitations and Implications}

This study has some limitations, including the small sample size as well as the ratio of males to females which represented almost one-third. To facilitate the effective implications of EI in health organizations, it may be helpful in the future to investigate the internal factors that predict the levels of EI during the COVID-19 crisis, including other healthcare providers and patients in different stages. One way to do so would be to develop reliable and consistent means of key performance indicators that are related to various EI levels among nurses and other healthcare professionals, including communication skills and burnout domains. These assessments could then be administered routinely, in the form of a checklist for instance, to the benefit of both the nursing and the health institution. Moreover, it would be advantageous for researchers to examine the impact of hospital leadership on EI and JP, as well as explore the relationships between EI, burnout, and employee turnover among nurses during such crisis.

\section{Conclusion}

The study found clear evidence of strong links between nurses' levels of EI and their reported JP. In general, nurses have high EI, especially among critical care medically oriented professionals. Results should be interpreted with caution. These findings may suggest that constructing an empathic environment among healthcare providers may yield significant benefits in the form of increased employee performance and an increase in operational best practices in patientcentered institutions. It is recommended that EI may be treated as a valuable asset among nurses, and that it could be incorporated into healthcare practice guidelines and performance evaluations.

\section{Data Sharing Statement}

The datasets used and/or analyzed in the current study are available from the corresponding author on reasonable pedagogical request.

\section{Ethics Approval and Consent to Participate}

This study was ethically approved by the Medical Committee at King Saud University (IRB-20-04E). There was no written consent, as replying to the assigned online survey implied agreement to participate, and the committee approved this procedure.

\section{Acknowledgments}

The author extends his appreciation to the Deanship of Scientific Research at King Saud University and the Research Center at the College of Business Administration for supporting this work.

\section{Disclosure}

The author certifies that there are no conflicts of interest with any financial organization or anything else regarding the material discussed in the manuscript.

\section{References}

1. Sommer SA, Howell JM, Hadley CN. Keeping positive and building strength: the role of affect and team leadership in developing resilience during an organizational crisis. Group Organ Manag. 2016;41 (2):172-202. doi:10.1177/1059601115578027

2. Nightingale S, Spiby H, Sheen K, Slade P. The impact of emotional intelligence in health care professionals on caring behaviour towards patients in clinical and long-term care settings: findings from an integrative review. Int J Nurs Stud. 2018;80:106-117. doi:10.1016/j. ijnurstu.2018.01.006

3. Shooshtarian Z, Ameli F, Aminini LM. The effect of labor's emotional intelligence on their job satisfaction, job performance and commitment. Iran J Manag Stud. 2013;6(1):27-43.

4. Restubog SLD, Ocampo ACG, Wang L Taking control amidst the chaos: emotion regulation during the COVID-19 pandemic. Elsevier; 2020. doi: $10.1016 /$ j.jvb.2020.103440

5. Fabio AD, Palazzeschi L, Asulin-Peretz L, Gati I. Career indecision versus indecisiveness: associations with personality traits and emotional intelligence. J Career Assess. 2013;21(1):42-56. doi:10.1177/ 1069072712454698

6. Goleman D, Boyatzis RE, McKee A. Primal Leadership: Unleashing the Power of Emotional Intelligence. USA: Harvard Business Press; 2013.

7. Coetzee M, Harry N. Emotional intelligence as a predictor of employees' career adaptability. J Vocat Behav. 2014;84(1):90-97. doi:10.1016/j.jvb.2013.09.001

8. Talman K, Hupli M, Rankin R, Engblom J, Haavisto E. Emotional intelligence of nursing applicants and factors related to it: a cross-sectional study. Nurse Educ Today. 2020;85:104271. doi:10.1016/j.nedt.2019.104271

9. Birks Y, McKendree J, Watt I. Emotional intelligence and perceived stress in healthcare students: a multi-institutional, multi-professional survey. BMC Med Educ. 2009;9(1):61. doi:10.1186/1472-6920-9-61

10. Bailey C, Murphy R, Porock D. Professional tears: developing emotional intelligence around death and dying in emergency work. J Clin Nurs. 2011;20(23-24):3364-3372. doi:10.1111/j.1365-2702.2011.03860.x

11. Webb CA, Schwab ZJ, Weber M, et al. Convergent and divergent validity of integrative versus mixed model measures of emotional intelligence. Intelligence. 2013;41(3):149-156. doi:10.1016/j.intell.2013.01.004 
12. Hülsheger UR, Alberts HJ, Feinholdt A, Lang JW. Benefits of mindfulness at work: the role of mindfulness in emotion regulation, emotional exhaustion, and job satisfaction. J Appl Psychol. 2013;98 (2):310. doi:10.1037/a0031313

13. Czabanowska K, Malho A, Schröder-Bäck P, Popa D, Burazeri G. Do we develop public health leaders?-Association between public health competencies and emotional intelligence: a cross-sectional study. BMC Med Educ. 2014;14(1):83. doi:10.1186/1472-6920-14-83

14. Landa JMA, López-Zafra E. The impact of emotional intelligence on nursing: an overview. Psychology. 2010;1(1):50-58. doi:10.4236/ psych. 2010.11008

15. Doherty EM, Cronin PA, Offiah G. Emotional intelligence assessment in a graduate entry medical school curriculum. BMC Med Educ. 2013;13(1):38. doi:10.1186/1472-6920-13-38

16. Aftab HA. Study of job satisfaction and IT's impact on the performance in the banking industry of Pakistan. Int J Bus Manag Soc Res. 2012;3(19):174-180.

17. Ram P. Relationship between job satisfaction and job performance in the public sector-a case study from India. Int $J$ Acad Res Econ Manag Sci. 2013;2(2):16.

18. Al-Ahmadi H. Factors affecting performance of hospital nurses in Riyadh Region, Saudi Arabia. Int J Health Care Qual Assur. 2009;22 (1):40-54. doi:10.1108/09526860910927943

19. Alessandri G, De Longis E, Eisenberg N, Hobfoll SE. A multilevel moderated mediational model of the daily relationships between hassles, exhaustion, ego-resiliency and resulting emotional inertia. J Res Pers. 2020;85:103913. doi:10.1016/j.jrp.2020.103913

20. Marcus-Varwijk AE, Peters LL, Visscher TL, Smits CH, Ranchor AV, Slaets JP. Impact of a nurse-led health promotion intervention in an aging population: results from a quasi-experimental study on the "Community health consultation offices for seniors". J Aging Health. 2020;32(1):83-94. doi:10.1177/0898264318804946

21. Wong C-S, Law KS. The effects of leader and follower emotional intelligence on performance and attitude: an exploratory study. Leadersh $Q$. 2002;13(3):243-274. doi:10.1016/S1048-9843(02)00099-1

22. Lucas V, Laschinger HK, Wong CA. The impact of emotional intelligent leadership on staff nurse empowerment: the moderating effect of span of control. J Nurs Manag. 2008;16(8):964-973. doi:10.1111/ j.1365-2834.2008.00856.x

23. Freshman B, Rubino L. Emotional intelligence: a core competency for health care administrators. Health Care Manag. 2002;20(4):1-9. doi:10.1097/00126450-200206000-00002

24. Alshammari F, Pasay-an E, Gonzales F, Torres S. Emotional intelligence and authentic leadership among Saudi nursing leaders in the Kingdom of Saudi Arabia. J Prof Nurs. 2020. doi:10.1016/j. profnurs.2020.04.003

25. Huang H, Liu L, Yang S, Cui X, Zhang J, Wu H. Effects of job conditions, occupational stress, and emotional intelligence on chronic fatigue among Chinese nurses: a cross-sectional study. Psychol Res Behav Manag. 2019;12:351-360. doi:10.2147/PRBM.S207283

26. Coleman D. Emotional Intelligence. Bantam, New York, USA; 1995.

27. Trivellas P, Gerogiannis V, Svarna S. The impact of emotional intelligence on job outcomes and turnover intention in health care. ICININFO-2011, Adv Inf Process Manag. 2011;1:356-360.

28. Mo Y, Deng L, Zhang L, et al. Work stress among Chinese nurses to support Wuhan in fighting against COVID-19 epidemic. J Nurs Manag. 2020;28(5):1002-1009. doi:10.1111/jonm.13014

29. Cheshire MH, Strickland HP, Ewell PJ. Measured emotional intelligence in baccalaureate nursing education: a longitudinal study. Nurs Educ Perspect. 2020;41(2):103-105. doi:10.1097/01.NEP.0000000000000476

30. Ebrahim SH, Memish ZA. COVID-19: preparing for superspreader potential among Umrah pilgrims to Saudi Arabia. Lancet. 2020;395 (10227):e48. doi:10.1016/S0140-6736(20)30466-9

31. Ebrahim SH, Memish ZA. Saudi Arabia's measures to curb the COVID-19 outbreak: temporary suspension of the Umrah pilgrimage. J Travel Med. 2020;27(3):1-2. doi:10.1093/jtm/taaa029
32. Wu W, Zhang Y, Wang P, et al. Psychological stress of medical staffs during outbreak of COVID-19 and adjustment strategy. J Med Virol. 2020:1-9. doi:10.1002/jmv.25914

33. Almutairi KM, Alonazi WB, Vinluan JM, et al. Health promoting lifestyle of university students in Saudi Arabia: a cross-sectional assessment. BMC Public Health. 2018;18(1):1093. doi:10.1186/s12889-018-5999-z

34. Mann K, van der Vleuten C, Eva K, et al. Tensions in informed self-assessment: how the desire for feedback and reticence to collect and use it can conflict. Acad Med. 2011;86(9):1120-1127. doi:10.1097/ACM.0b013e318226abdd

35. Krejcie RV, Morgan DW. Determining sample size for research activities. Educ Psychol Meas. 1970;30(3):607-610. doi:10.1177/ 001316447003000308

36. Podsakoff PM, MacKenzie SB, Lee J-Y, Podsakoff NP. Common method biases in behavioral research: a critical review of the literature and recommended remedies. J Appl Psychol. 2003;88 (5):879-903. doi:10.1037/0021-9010.88.5.879

37. Koopmans L, Bernaards CM, Hildebrandt VH, Schaufeli WB, de Vet Henrica C, van der Beek AJ. Conceptual frameworks of individual work performance: a systematic review. J Occup Environ Med. 2011;53(8):856-866. doi:10.1097/JOM.0b013e318226a763

38. Hunt SD, Sparkman RD, Wilcox JB. The pretest in survey research: issues and preliminary findings. J Mark Res. 1982;19(2):269-273. doi:10.1177/002224378201900211

39. Nunnally JC. Psychometric Theory 3E. Tata McGraw-Hill Education; 1994.

40. Deshpande SP, Joseph J. Impact of emotional intelligence, ethical climate, and behavior of peers on ethical behavior of nurses. $J$ Bus Ethics. 2009;85(3):403. doi:10.1007/s10551-008-9779-z

41. Cadman C, Brewer J. Emotional intelligence: a vital prerequisite for recruitment in nursing. $J$ Nurs Manag. 2001;9(6):321-324. doi:10.1046/j.0966-0429.2001.00261.x

42. McCALLIN A, Bamford A. Interdisciplinary teamwork: is the influence of emotional intelligence fully appreciated? J Nurs Manag. 2007;15(4):386-391. doi:10.1111/j.1365-2834.2007.00711.x

43. Arora S, Ashrafian H, Davis R, Athanasiou T, Darzi A, Sevdalis N. Emotional intelligence in medicine: a systematic review through the context of the ACGME competencies. Med Edu. 2010;44 (8):749-764. doi:10.1111/j.1365-2923.2010.03709.x

44. McQueen AC. Emotional intelligence in nursing work. $J$ Adv Nurs. 2004;47(1):101-108. doi:10.1111/j.1365-2648.2004.03069.x

45. Moghadam AH, Tehrani M, Amin F. Study of the relationship between emotional intelligence (EI) and management decision making styles. World Appl Sci J. 2011;12(7):1017-1025.

46. Vahidi M, Namdar Areshtanab H, Arshadi Bostanabad M. The relationship between emotional intelligence and perception of job performance among nurses in north west of Iran. Scientifica. 2016;2016:1-5. doi:10.1155/2016/9547038

47. Al-Hamdan Z, Oweidat IA, Al-Faouri I, Codier E. Correlating emotional intelligence and job performance among jordanian hospitals' registered nurses. $J$ Adv Nurs. 2017;52:12-20. doi:10.1111/nuf.12160

48. Wu Y-C. Job stress and job performance among employees in the Taiwanese finance sector: the role of emotional intelligence. Soc Behav Pers. 2011;39(1):21-31. doi:10.2224/sbp.2011.39.1.21

49. Akhtar W, Ghufran H, Husnain M, Shahid A. The effect of emotional intelligence on employee's job performance: the moderating role of perceived organizational support. J Account Mark. 2017;6(3):2-8. doi:10.4172/2168-9601.1000243

50. Akhtar M, Shabir A, Safdar M, Akhtar M. Impact of emotional intelligence on turnover intentions: the role of organizational commitment and perceive organizational support. J Account Mark. 2017;6(4):1-7. doi:10.4172/2168-9601.1000259

51. Ali SR, Fall K, Hoffman T. Life without work: understanding social class changes and unemployment through theoretical integration. $J$ Career Assess. 2013;21(1):111-126. doi:10.1177/1069072712454 820 


\section{Publish your work in this journal}

Psychology Research and Behavior Management is an international, peer-reviewed, open access journal focusing on the science of psychology and its application in behavior management to develop improved outcomes in the clinical, educational, sports and business arenas. Specific topics covered in the journal include: Neuroscience, memory and decision making; Behavior modification and management; Clinical applications; Business and sports performance management; Social and developmental studies; Animal studies. The manuscript management system is completely online and includes a very quick and fair peer-review system, which is all easy to use. Visit http://www. dovepress.com/testimonials.php to read real quotes from published authors. 